\title{
Erratum to: Characterization of Pharmacokinetics in the Göttingen Minipig with Reference Human Drugs: An In Vitro and In Vivo Approach
}

Floriane Lignet' • Eva Sherbetjian' • Nicole Kratochwil' • Russell Jones ' Claudia Suenderhauf ${ }^{2}$.

Michael B. Otteneder ${ }^{\prime} \cdot$ Thomas Singer $^{\prime} \cdot$ Neil Parrott $^{\prime}$

Published online: 22 August 2016

(C) Springer Science+Business Media New York 2016

\section{Erratum to: Pharm Res}

DOI: I0.1007/s I | 095-0 I 6-1982-5

The second author's last name was wrongly spelled "Sherbetijan" in the original published article. The correct spelling is "Sherbetjian " as shown in this erratum and as updated in the original article.

The online version of the original article can be found at http://dx.doi. org/l0.1007/s | 1095-0 |6-1982-5.

\section{Floriane Lignet}

floriane.lignet@ens-lyon.fr

Pharmaceutical Sciences, Roche Pharmaceutical Research and Early

Development, F. Hoffmann - La Roche, Ltd, Basel, Switzerland

2 Klinische Pharmakologie \& Toxikologie, Universitätsspital Basel,

Basel, Switzerland 